\title{
La forma urbana del medio ambiente construido: Hacia una propuesta de estructuración para el instrumento Plan Regulador Comunal
}

Luz Alicia Cárdenas Jirón

\section{Filiación}

Arquitecto, Profesora Asistente e Investigadora del Departamento de Urbanismo, Facultad de Arquitectura y Urbanismo, UCh., Magister en Urbanismo, (U. Chile) y Master in Sciencies in Urban Development Planning, (U. London)

\section{Resumen}

La forma urbana del medio ambiente construido es el elemento central de este artículo, abordado desde dos perspectivas: en primer lugar la crítica de la forma urbana resultante de un instrumento de planificación y en segundo lugar una propuesta de estructuración de la forma urbana para el Plan Regulador Comunal. Con este objeto, se presenta un modelo cartográfico para entregar una pauta metodológica de los aspectos relevantes a la forma urbana que debieran tomarse en cuenta al momento de planificar y gestionar la ciudad.

\section{Palabras claves}

Forma urbana, modelo cartográfico, instrumento de planificación urbana, Plan Regulador Comunal (Chile)

\begin{abstract}
The urban form of the built environment is the core element of this article. Two approaches have been developed to deal with it, firstly, a criticism of the urban form as a result of the town planning instrument and secondly a proposal to structure the urban form for Plan Regulador Comunal. Given that a cartographic model is showed as an example to deal with relevant issues in relation to the urban form. The model tries to give a methodological guide to the urban planners and managers.
\end{abstract}

\section{Kay Words}

Urban form, cartographic model, town planning instrument, Plan Regulador Comunal (Chile).

\section{Sumario}

Introducción

1.- El Plan Regulador Comunal y su relación con el Diseño Urbano

2. Los modelos como instrumentos de apoyo

3. Comentarios y conclusiones.

Referencias 


\section{Introducción}

El Plan Regulador Comunal y su relación con el Diseño Urbano es un aspecto deficitario en la realidad chilena; una hipótesis explicativa de este hecho es que la actual metodología para confeccionar un Plan Regulador Comunal en Chile no considera un aspecto clave de la ciudad: la forma urbana. (Cárdenas, 1999). Con esta afirmación se abre una puerta a la investigación propositiva. En esta búsqueda, aparecen como relevantes aquellos instrumentos y técnicas informáticas que permiten crear un sistema de apoyo a la planificación urbana. En efecto, los sistemas de información geográfica SIG, el diseño asistido por computador, CAD; los mapas asistidos por computador, CAM; los modelos cartográficos; la visualización en 3D; la realidad virtual; constituyen técnicas y/o métodos para la modelación y el análisis espacial urbano, sea bidimensional, tridimensional u otro. (Cárdenas et al., 1998), (Hall, 1993).

El objetivo de esta búsqueda es proponer un método que incorpore conceptos e imágenes para simular la estructura de la forma urbana actual y potencial de una realidad comunal, en este caso Maipú. Para ello se ha decidido realizar un modelo cartográfico asociado a una visualización $3 \mathrm{D}$, porque se cree que con ello se lograra de mejor forma el objetivo inicial. El resultado final esperado es obtener un instrumento operativo de apoyo a la planificación urbana, en un aspecto considerado clave y deficitario en la actualidad, como es la estructura morfológica de la ciudad.

El ejemplo tomado en cuenta ha sido la comuna de Maipú, situado en la periferia sur poniente de Santiago, la cual ha experimentado un crecimiento demográfico explosivo en los últimos veinte años impactando fuertemente en su urbanización y en la forma urbana. Algunos de los efectos han sido el descontrol de la forma urbana y caos de la estructura espacial urbana. Se cree que ambas materias serían posibles de manejar con una base conceptual orientada en "hacer urbanismo" más que en "hacer urbanización", por parte de los tomadores de decisión de la municipalidad en estudio.

\section{1.- EI Plan Regulador Comunal y su relación con el Diseño Urbano}

Cabe recordar que la planificación de los usos de suelo y las formas de ocupación del suelo es el resultado de la aplicación de normativas del Plan Regulador Comunal y Planes Seccionales. Vale decir, estos instrumentos legales son los que permiten estas formas de ocupación del territorio comunal. En efecto, el documento legal denominado Plan Regulador Comunal es un instrumento que norma sobre los límites urbanos, la red vial estructurante, los usos de suelo, las formas de ocupación y de subdivisión predial. Por tanto el emplazamiento de la arquitectura y los espacios públicos relevantes así como la definición de la trama o red de calles es posible de regular por el Plan, el cual puede permitir o prohibir las propuestas de los proyectos individuales que van conformando la ciudad.

La práctica de la aprobación de los proyectos arquitectónicos y urbanísticos según la Ordenanza del Plan Regulador Comunal es una función que le compete al Estado y la realizan funcionarios municipales, generalmente de profesión arquitecto, según la estricta aplicación de la ley en su forma y no en su espíritu. El funcionario podría 
aplicar criterios urbanísticos teniendo presente una visión de conjunto de la ciudad y no una visión de parcialidades inconexas al momento de otorgar el permiso municipal, pero es una facultad no siempre ejercida.

En este sentido, se pueden destacar algunos buenos ejemplos de intervenciones urbanísticas en la ciudad de Santiago. En el período de 1872-1875, el intendente chileno Don Benjamín Vicuña Mackenna propone un proyecto de transformación de la ciudad de Santiago bastante exitoso en su época (Hermosilla, 1973) y en el periodo 1929 - 1931, el urbanista vienés Karl Brunner propone también un proyecto de transformación de la ciudad de Santiago, y más tarde realiza la confección del Plan Oficial de Urbanización de la Comuna de Santiago en 1934 que llegó a aprobarse solamente seis años después, en 1939 por la Junta de Vecinos de la I. Municipalidad de Santiago y se constituyó entonces en el Plan Regulador de la Comuna de Santiago, (FAU, 1996).

Ambos destacados personajes pudieron realizar estas intervenciones no solamente por su talento y visión prospectiva sino también porque tenía apoyo político y competencias legales para actuar sobre la ciudad. En el caso de Vicuña Mackenna, en su calidad de Intendente tenía el apoyo del presidente Balmaceda y las leyes que lo facultaban para hacer modificaciones especialmente de calles en la ciudad. En el caso de Brunner, fue contratado por el Gobierno de Chile (Ministerio de Obras Publicas) con el respaldo político del presidente Ibáñez del Campo y luego fue contratado por la I. Municipalidad de Santiago para formular el documento legal denominado Plan Oficial de Urbanización que controlaba no solo el ancho de calles de la trama sino también la altura de los edificios, su homogeneidad arquitectónica, la localización de espacios abiertos significativos y la arquitectura relevante para transformar la comuna de Santiago.

A pesar de corresponder a distintos estados de desarrollo nacional y urbano, pues median 55 años entre las dos intervenciones, ambos proyectos contemplan la integración de la planificación de usos de suelo con el diseño del espacio público, la arquitectura y las obras civiles. Vale decir, se observa una dialéctica armónica entre el plano y el espacio público, o dicho de otro modo entre la planificación de la ciudad y el diseño del espacio urbano apoyado por la arquitectura.

A Mackenna, a fines del siglo XIX, le concernían aspectos como controlar la extensión de la ciudad, mejorar la conectividad entre los barrios y accesibilidad, actuar sobre la higiene y salubridad de los barrios más pobres, el hermoseamiento de los espacios públicos (calles), la creación de parques urbanos y plazas y el control de las inundaciones del río. Tuvo como asesor y jefe de proyecto al ingeniero Ansart quien realizó los tajamares del río Mapocho y el puente de Cal y Canto. De las numerosas obras y proyectos que realizo en apenas tres años de intendente, se destacan las más relevantes como la habilitación del Cerro Sta. Lucia como Parque, el camino de Cintura o circunvalación que delimitaba el arrea urbanizable y los tajamares del río Mapocho. Esto se concretó jurídicamente con la Ley de transformación y embellecimiento de Santiago en 1874. 
A Brunner, a comienzos del siglo XX, le interesaba la estructura morfológica de la ciudad vinculada al Plan de Urbanismo, de hecho sus obras..." constituyen demostraciones fehacientes del ejercicio urbanístico que es posible desarrollar desde la arquitectura..." (Figueroa, 1996). Concebía la construcción de la ciudad como espacio público que tenía que planificar, en este sentido la dicotomía entre plan y proyecto que hoy se plantea fue resuelta por Brunner (Cortés, 1996), pues este consideraba la obra arquitectónica no solamente la construcción de edificios sino también los paseos públicos o espacios de la ciudad.

Entre sus actuaciones más importantes pueden mencionarse la plaza al norte de la Moneda, la uniformidad arquitectónica del barrio cívico; la Avenida Central, la no construcción de rascacielos en torno al edificio de La Moneda; la unión de los parques Forestal y Providencia; la eliminación del ferrocarril de circunvalación y estaciones de Sta. Elena, Ñuñoa, Providencia para construir otra pieza clave de la composición urbana y del bien común, el actual Parque Bustamante; el Plan Regulador de Santiago (aprobado en 1939); la visión de un ferrocarril subterráneo y una Avenida Norte Sur.

Esta integración de la percepción bidimensional y tridimensional de la ciudad pareciera ser que hoy está completamente perdida y no figura en los instrumentos de planificación urbana vigentes en Chile, los llamados Planes Reguladores. Como afirman algunos planificadores norteamericanos, (Gallion y Eisner, 1986) la planificación clásica de la ciudad ${ }^{1}$ ha sido reemplazada por una planificación económica de la ciudad ${ }^{2}$.

Esta situación es particularmente notoria en la morfología de la periferia metropolitana chilena. Una explicación de este fenómeno puede comprenderse a través del estudio y seguimiento de las Políticas de Desarrollo Urbano de los ochenta y noventa, (MINVU) junto con las Políticas Habitacionales (SERVIU), la planificación urbana y regional vía Planos Reguladores Comunales y Regionales (SERREMI/MINVU), los modelos de crecimiento físico de la metrópolis (AUCA, 1979) (Joinet,1996) y la estructura de precios del mercado de la tierra, (Trivelli, 1997).

De modo que cabe preguntarse: ¿el instrumento legal denominado Plan Regulador es eficiente por sí mismo para lograr objetivos de ordenamiento de la ciudad? o bien ¿ es un instrumento que requiere ser modificado y/o complementado con otros mecanismos y facultades legales?

El autor Raposo (Raposo, 1995) comparte esta postura cuando afirma que el Estado de Chile ejerce importantes fuerzas modeladoras del ordenamiento urbano, siendo una de ellas la planificación urbana. Y que en el actual contexto de la modernización debieran revisarse las competencias de la planificación urbana. El autor afirma:

\footnotetext{
${ }^{1}$ Planificación clásica de la ciudad, la entienden como la conjunción de la arquitectura, espacio público y trama de la ciudad y condicionantes naturales. Ejemplo, Washington.

2 Planificación de la ciudad comercial la entienden como aquella que responde a principios económicos como es el logro de la obtención de la máxima rentabilidad a través del negocio inmobiliario y la subdivisión predial. Esta planificación es indiferente a las condicionantes naturales del terreno, se juega en la explotación del predio y arquitectura autónoma respecto al contexto, siendo el espacio público la resultante de una trama vial eficiente al transporte. Ejemplo; New York.
} 
...frecuentemente suele ponerse en entredicho las capacidades de los planificadores urbanos o la eficacia de los instrumentos de planificación para mejorar o sostener el orden de la ciudad. Generalmente se olvida que la planificación urbana no es más que la expresión, a nivel de racionalidad instrumental, de las competencias jurídicas acordadas por la sociedad a la administración del Estado. Estas competencias normalmente indican el nivel de articulación de intereses alcanzado en torno a objetivos de equidad social...

Partiendo de esta premisa se podría sostener que efectivamente la relación entre planificación urbana y diseño urbano es una de las deficiencias o carencias que el Plan Regulador no contempla dentro de sus facultades, aunque existan artículos específicos destinados a precisar alturas de edificación, densidades de ocupación del terreno, distanciamientos a los medianeros, etc.

Del mismo modo, el plan regulador se pronuncia sobre los perfiles geométricos de las calles que constituyen la red vial estructurante. Más aún, el año 1997, el Ministerio de la Vivienda y Urbanismo realizó un estudio para entregar una metodología que estime la capacidad vial de la red, tema hasta entonces inexistente, pero nada se menciona acerca del significado espacial tridimensional de esa red. En otras palabras, carencia total del concepto de espacio público en dicho estudio. (MINVU, 1997). En efecto, las características de la red de espacios públicos y su vinculación con la arquitectura no es un tema incorporado explícitamente en las facultades del instrumento legal ni en las nuevas metodologías específicas para dimensionar la red. Se podría afirmar que el diseño urbano propiamente tal es solamente la resultante de la aplicación de proyectos individuales aprobados legalmente por el Plan, pero no habría una voluntad de diseño para concebir a la ciudad como un proyecto de urbanismo, (Pol, 1992).

La falta de una relación dialéctica entre las tipologías edificatorias y los espacios urbanos que configuran la morfología de la ciudad requiere previamente de un "proyecto de urbanismo" que bosqueje los lineamientos generales para la ciudad, no solamente en términos bidimensionales sino también tridimensionales, pues así se construyen las ciudades en la realidad.

Actualmente el documento legal Plan Regulador Metropolitano (MINVU, 1994) define los límites urbanos, el zoning, las redes viales estructurantes y los equipamientos colectivos de carácter metropolitano, pero carece de una propuesta de ciudad que incorpore los elementos claves del urbanismo en la morfología de la ciudad. A su vez, el Plan Regulador Comunal que maneja una escala menor y que está supeditado al Plan Regulador Metropolitano, podría también bosquejar una organización espacial urbana a escala de la comuna y del barrio, teniendo presente que la ciudad se construye por etapas. Según Bonet: (Bonet, 1989).

... no hay que olvidar que la ciudad es un proceso continuo de crecimiento, transformación, modificación y cambio... y las estructuras urbanas son el producto de los modos de crecimiento y formación del tejido urbano que combinados con los sistemas compositivos forman la trama de la ciudad... 
En términos de diseño urbano, se observa en la comuna de Maipú que en las nuevas urbanizaciones, los paños de terreno rural se van cubriendo por vastos sectores habitacionales que utilizan los antiguos límites prediales rurales para definir la trama de calles. Además se observa una textura similar, pero un grano muy pequeño en el tejido urbano, comparado con la urbanización anterior a los años ochenta. La relación espacio construido-espacio vacío que muestra el nolly plan, evidencia una gran monotonía y refleja un criterio de racionalización económica y constructiva que utiliza la ocupación máxima del lote para cada vivienda dentro del jibarizado concepto de "ciudad jardín" (Cherry, 1980).

Esto parece obedecer a la búsqueda de una máxima rentabilidad del suelo urbano y la edificación en el proceso de gestión inmobiliaria, con lo cual aumentan las densidades de ocupación del suelo y disminuye la superficie de $\mathrm{m} 2$ por habitante en cada vivienda. En contraste a lo anterior aparece también extensas superficies edificadas destinadas a locales comerciales y recreación intramuros (mall) sobre extensos terrenos libres destinados a estacionamientos.

El "mall" es conocido como las catedrales del consumismo pues ellos representan un estereotipo de las construcciones dedicadas a la venta de productos y servicios. En términos arquitectónicos son edificios ciegos, encerrados en sí mismo y entregando muros opacos a la ciudad. En términos urbanísticos se imponen en el tejido urbano y sin consideración alguna respecto de la configuración espacial del entorno. Esto puede interpretarse como la expresión arquitectónica y urbanística de la filosofía consumista donde, además, predomina la política del libre mercado en el modelo de urbanización seleccionado. Como afirma Fernández Alba, el arquitecto español contemporáneo, lo que caracteriza la crisis actual de la metrópolis de hoy en relación con su configuración ambiental es la dependencia y servidumbre que las últimas arquitecturas de la ciudad tienen con respecto al proceso de mercantilismo y de los diferentes sistemas de producción del espacio urbano, (Alba, 1990).

De este modo, la arquitectura se constituye en un gran aparato escénico que se torna indiferente a su entorno transformándose en una construcción sin memoria que se consolida como monumento en el desorden metropolitano. El nuevo orden económico global produce un cambio en la sociedad, que pasa de la cultura de la calidad por la cultura de la cantidad y el autor comenta:

... frente a las corrientes neoliberales de fin de siglo, se hace imprescindible el desarrollo de una teoría crítica, que sostenga de una vez por todas, que el suelo y el espacio no deben legitimarse como mercancía, junto a una política de la ciudad que haga posible que el territorio de ésta sea cada vez menos un negocio privado y más un bien social...

Esta postura bien podría ajustarse al modelo de urbanización de crecimiento en la periferia sur poniente metropolitana de Santiago, pues allí se van localizando los segmentos poblacionales de menos recursos económicos y por ende con escasas posibilidades de entrar libremente en un juego mercantilista del espacio urbano. 


\section{2.- Los modelos como instrumentos de apoyo}

Los modelos son una representación simplificada de la realidad que tiene por objeto comprenderla mejor. Los modelos poseen distintas clasificaciones de acuerdo a tres criterios: i) ¿para qué función están hechos?; ii) ¿de qué están hechos?; y iii) ¿cómo tratan la dimensión temporal?

En respuesta a la primera pregunta, los modelos pueden clasificarse en cuatro tipos de acuerdo a la función, a saber: los descriptivos; los predictivos, los exploratorios, y los de planeamiento. En respuesta a la segunda pregunta, hay distintos tipos de modelos según sean los medios utilizados para la modelación: físicos o conceptuales. Entre los primeros figuran las maquetas, las fotografías, los planos, y otros. Entre los segundos - y dependiendo si se emplean símbolos o lenguaje - pueden ser matemáticos o verbales. Finalmente los modelos pueden ser estáticos o dinámicos según sean las variables empleadas y su condición frente al tiempo. Así por ejemplo, la localización de las actividades humanas pueden variar muy rápido de un día para otro o incluso en horas, a diferencia del stock físico (suelo, edificios, calles) que cambian muy lentamente, (Echeñique, 1975).

Así, el modelo cartográfico se sitúa en un modelo de tipo descriptivo y exploratorio, pues pretende describir una realidad y explicar un fenómeno a través del análisis, en este caso el sistema urbano. Esta técnica simula la realidad mediante un esquema de causa-efecto configurado en base de un diagrama de flujos. Como su nombre lo indica, el modelo emplea una base cartográfica y opera como un sistema de información geográfica.

El modelo cartográfico es de tipo lineal, organizado en una red jerárquica, que a partir de variables de entrada, de tipo descriptivas, pueden producir variables derivadas producto del análisis - con nuevas salidas cartográficas; las cuales al superponerse con otras salidas de la red generan nueva información. De este modo, el modelo cartográfico puede contribuir a analizar un fenómeno a través de la desagregación de sus variables constituyentes. El modelo cartográfico está enraizado en el campo de la geografía y es ampliamente utilizado en el análisis espacial, por ejemplo la predicción de efectos de fenómenos naturales. (Bosque, 1992); (Gutiérrez, 1994).

\section{Planteamiento del problema}

El problema enunciado en la introducción y en el punto 1 se refiere a la carencia de un concepto - la forma urbana - en los contenidos para realizar un Plan Regulador Comunal $^{3}$.

En efecto, este instrumento de planificación urbana está compuesto de cuatro documentos que conforman un cuerpo legal para administrar el territorio comunal (MINVU, 1992), a saber:

\section{(1).- Memoria Explicativa}

\footnotetext{
${ }^{3}$ Ver Circular N¹1 D.D.U./ MINVU., 1979
} 
(2).- Ordenanza Local

(3).- Planos

(4).- Estudio de Factibilidad de Agua Potable y Alcantarillado

(1).- La Memoria Explicativa comprende el diagnóstico y los fundamentos de la propuesta de Plan Regulador. Recientemente se incorporaron otros dos estudios técnicos: el Estudio de Riesgo y el Estudio de Capacidad Vial. Además contiene todos los antecedentes gráficos, planimétricos y descriptivos, sobre aspectos demográficos, sociales, y económicos. Todo lo anterior tiene por objeto servir de base para las proposiciones y las alternativas de estructuración y gestión.

(2).- La Ordenanza Local es la normativa que fija los límites urbanos de sus centros poblados, el trazado de la vialidad estructurante; los usos de suelo permitidos, restringidos y prohibidos; el coeficiente de ocupación del suelo; las rasantes y distanciamientos; las alturas de edificación máxima y mínima; los tamaños prediales; los tipos de agrupamiento; y las normas sobre el equipamiento para todas las áreas urbanas y sistema urbano comunal sometido a planificación.

(3).-Los Planos son los documentos planimétricos (bidimensional), que expresan gráficamente, entre otros, el límite urbano, las áreas de extensión urbana con sus prioridades, las áreas de riesgo y de restricción, la zonificación, los usos de suelo, las densidades, la red vial estructurante, las áreas verdes y el equipamiento.

(4).-El Estudio de Factibilidad de Agua Potable y Alcantarillado, comprende la descripción, el análisis, el cálculo y proyecciones del sistema a fin de dotar o ampliar de agua potable y alcantarillado, de aguas servidas y lluvias, en función del crecimiento urbano proyectado.

Como puede verse, el tema de la definición de la forma urbana inserto en un proyecto de ciudad, está ausente en los contenidos actuales del Plan Regulador Comunal. Una de las consecuencias de este hecho es la desarticulación del espacio urbano, junto a la pérdida de los recursos naturales o arquitectónicos relevantes para la identidad de un lugar, lo cual sirve de base para la conciencia colectiva, el significado cultural, el sentido de pertenencia y apropiación del territorio por parte de la comunidad. Algunos autores que se refieren in extenso al tema. (Newman, 1976), (Rappoport, 1980), (Kostof, 1991), (Katz, 1994) (Trieb, 1988). En suma, una situación de este tipo repercute directamente en la calidad de vida para el habitante.

La importancia de controlar la forma urbana por el instrumento de planificación radica básicamente en dos aspectos: uno económico y otro semántico. El primero tiene relación con las rentas municipales que podrían captarse derivadas de la competencia por una localización de actividades comerciales y residenciales en ciudades vivibles y atractivas, cuya característica visible es precisamente la forma urbana.

Por ejemplo, muchas ciudades europeas occidentales de países con economías muy desarrolladas, contemplan políticas de inversión en patrimonio arquitectónico y urbanístico, pues eso representa parte significativa de su base económica, toda vez 
que una forma urbana estructurada y regulada armónicamente mediante una normativa municipal, da un encanto físico a la ciudad.

Esta situación atrae turistas y negocios de transacciones bursátiles, como también de eventos internacionales (convenciones, congresos, festivales, etc.), a la ciudad que tiene ventaja comparativa frente a otra localización, (CEC, 1990). Este principio también es posible aplicarlo a una menor escala, en la comuna, pues las mayores rentas municipales podrían significar una mayor inversión en gasto público para infraestructura colectiva y un sustancial mejoramiento del medio ambiente urbano, lo cual incide en la calidad de vida de sus moradores.

Desde el punto de vista semántico, es importante señalar que el comportamiento del ser humano en su interacción con el medio ambiente construido obedece esencialmente a relaciones topológicas, las cuales se estructuran en base a la forma urbana. (Gutiérrez, 1994), (Lynch, 1960), (Hall, 1966). Esto significa, por ejemplo, que el individuo utiliza referencias espaciales de tipo cualitativo del siguiente orden: cerca de, arriba de, detrás de, a la izquierda de, entre, al oeste de, etc., para orientarse y dar indicaciones sobre como desplazarse en una ciudad cualquiera.

Esto lleva a plantear la necesidad de incorporar el tema de la forma urbana y para ello se propone el desarrollo de un modelo cartográfico que permita integrar conceptos que tengan una fuerte incidencia en la configuración espacial urbana. Así, manejarlos gráficamente, de modo de instrumentalizar un método de_trabajo que sea fácilmente operable en distintos contextos comunales en Chile. Uno de los beneficios de este método, es que el uso del lenguaje gráfico, contribuye de un modo significativo a una mejor comprensión de la propuesta, sea por parte del arquitecto, urbanista, gestor inmobiliario, comunidad, planificador, etc. (Hall, 1993).

\section{2.- Desarrollo y propuesta del modelo}

El modelo cartográfico diseñado para lograr como resultado una "Definición de la Estructura Morfológica para Plan Regulador Comunal" aparece en la Figura №1. Como puede verse, el modelo está constituido por tres componentes principales: el modelo volumétrico, la planimetría de la estructura morfológica, y la localización de áreas potenciales de mayor demanda. Estos dos últimos pueden realizarse con un Sistema de Información Geográfica SIG, en cambio el primero requiere de otra técnica, la visualización 3D. En este artículo se desarrollaran las opciones posibles dentro del sistema de información geográfica.

El caso de estudio elegido es la comuna de Maipú, ubicado en la periferia de la metrópolis de Santiago, de creciente expansión física y demográfica en la última década. Dinamismo que facilita una modelación cartográfica por la rapidez de los cambios ocurridos. (Figura No 0 ) 


\section{REVISTA DE URB UISN $_{0717-5051}$ ANISMO

La forma urbana del medio ambiente construido:

http://revistaurbanismo.uchile.cl

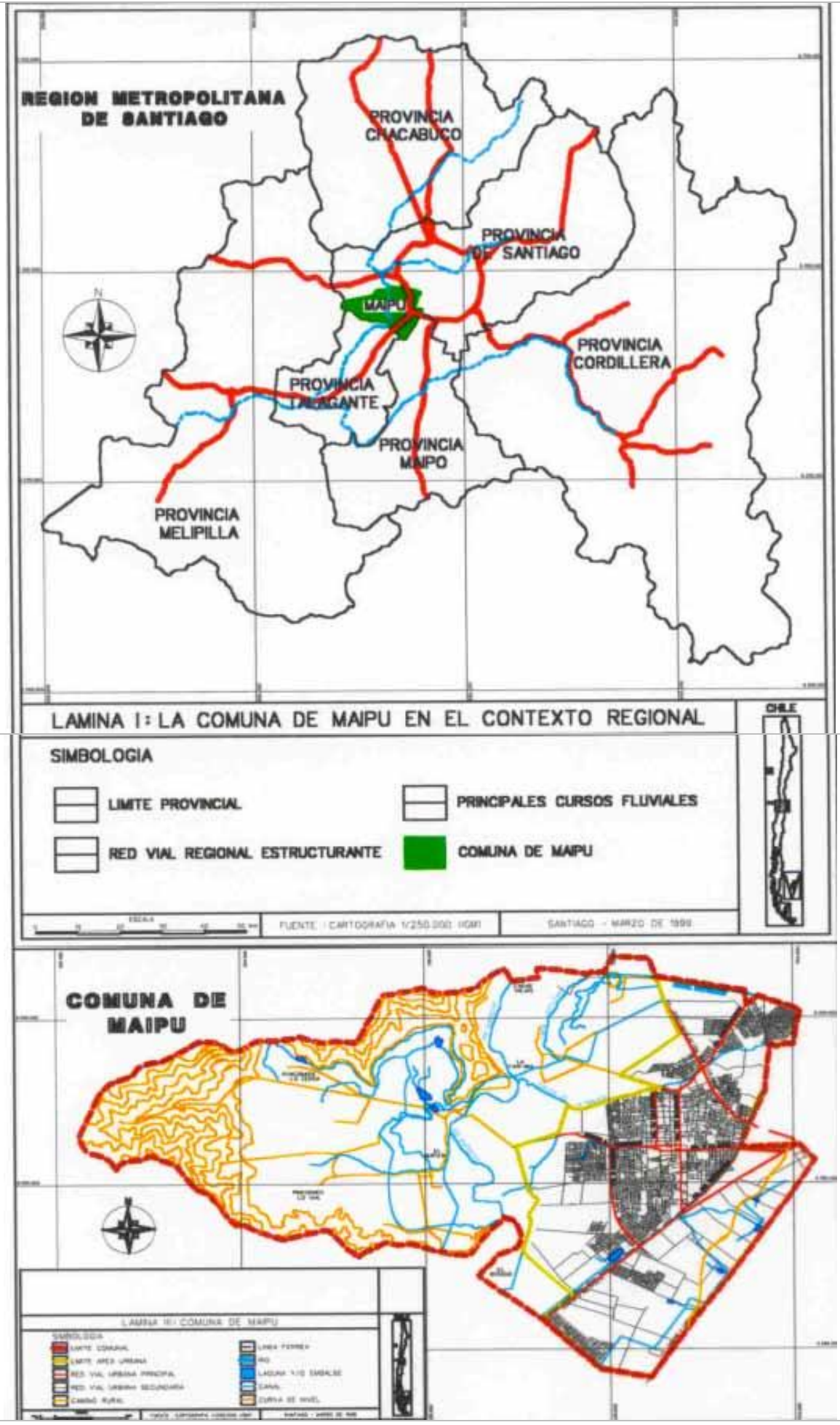




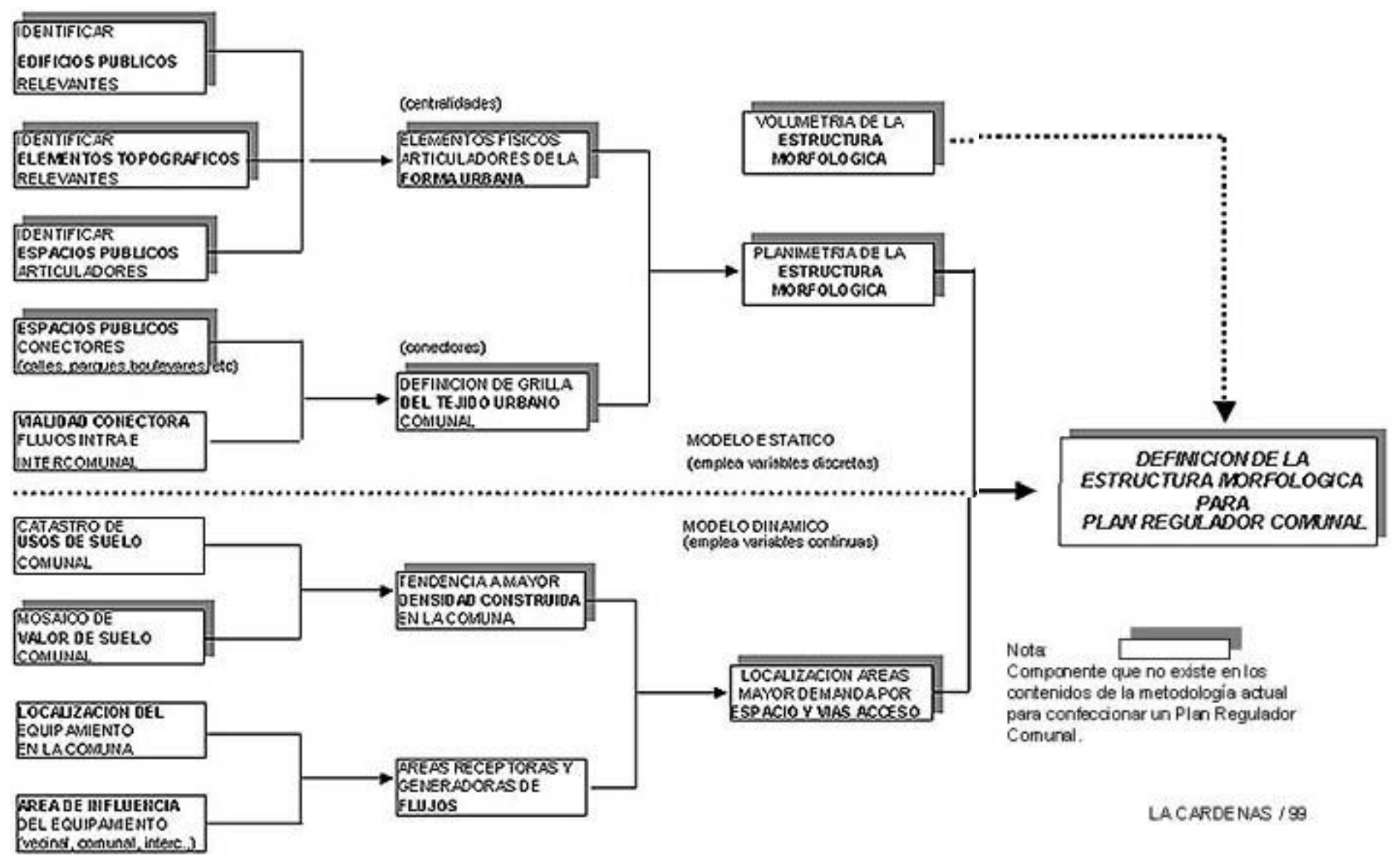

Figura 1

Descripción de la estructura morfológica para el plan regulador

En la Figura $\mathrm{N}^{\circ} 1$ se muestran las variables que debieran considerarse para llegar a definir la estructura morfológica de un asentamiento y así facilitar la formulación de una normativa en el Plan Regulador Comunal. Se han sombreado los cuadros que contienen variables que no están contempladas explícitamente en los contenidos actuales de la metodología para confeccionar un Plan Regulador Comunal, (ver 1, op. cit.) De un total de 9 variables, se han escogido 5 para la realización de un modelo estático y 4 para la realización de un modelo dinámico. Esta clasificación obedece a la naturaleza de las variables respecto a su velocidad de respuesta frente al cambio. Esto significa, aquellos componentes relativos a la infraestructura física o natural, cambian 
muy lentamente respecto de aquellos componentes asociados a las actividades urbanas, que pueden cambiar mucho más rápidamente.

En el modelo estático se presenta una red compuesta por dos variables fundamentales de la forma urbana: las centralidades y los conectores, los cuales arrojaran como resultado final la "planimetría de la estructura morfológica" (Figuras No11, No12, y N015). Los elementos primarios para definir las centralidades son tres: los edificios públicos, la topografía, y los espacios públicos. (Figuras N02, N03 y N04). Los elementos primarios para definir los conectores son dos: los espacios públicos y la vialidad intra e intercomunal. (Figuras $\mathrm{N}^{0} 5$ y $\mathrm{N}^{0} 6$ ).

Indice | Portada.

INVESTIGACIÓN ACADEMICOS

Chile - Extranjero

UCHILE - FAU - NACIONAL - INTERNACIONAL

\title{
LA FORMA URBANA DEL MEDIO AMBIENTE CONSTRUIDO: Hacia una propuesta de estructuración para el instrumento Plan Regulador Comunal $\stackrel{(1)}{ }$
}

\author{
Luz Alicia Cárdenas Jirón $\stackrel{(2)}{ }$
}

\section{Resumen}

La forma urbana del medio ambiente construido es el elemento central de este artículo, abordado desde dos perspectivas: en primer lugar la crítica de la forma urbana resultante de un instrumento de planificación y en segundo lugar una propuesta de estructuración de la forma urbana para el Plan Regulador Comunal. Con este objeto, se presenta un modelo cartográfico para entregar una pauta metodológica de los aspectos relevantes a la forma urbana que debieran tomarse en cuenta al momento de planificar y gestionar la ciudad.

Palabras claves: Forma urbana, modelo cartográfico, instrumento de planificación urbana, Plan Regulador Comunal.

\section{Abstract}

The urban form of the built environment is the core element of this article. Two approaches have been developed to deal with it, firstly, a criticism of the urban form as a result of the town planning instrument and secondly a proposal to structure the urban form for Plan Regulador Comunal. Given that a cartographic model is showed as an example to deal with relevant issues in relation to the urban form. The model tries to give a methodological guide to the urban planners and managers.

Kay Words: Urban form, cartographic model, town planning instrument, Plan Regulador Comunal.

\section{Introducción}


El Plan Regulador Comunal y su relación con el Diseño Urbano es un aspecto deficitario en la realidad chilena; una hipótesis explicativa de este hecho es que la actual metodología para confeccionar un Plan Regulador Comunal en Chile no considera un aspecto clave de la ciudad: la forma urbana. (Cárdenas, 1999). Con esta afirmación se abre una puerta a la investigación propositiva. En esta búsqueda, aparecen como relevantes aquellos instrumentos y técnicas informáticas que permiten crear un sistema de apoyo a la planificación urbana. En efecto, los sistemas de información geográfica SIG, el diseño asistido por computador, CAD; los mapas asistidos por computador, CAM; los modelos cartográficos; la visualización en 3D; la realidad virtual; constituyen técnicas y/o métodos para la modelación y el análisis espacial urbano, sea bidimensional, tridimensional u otro. (Cárdenas et al., 1998), (Hall, 1993)

El objetivo de esta búsqueda es proponer un método que incorpore conceptos e imágenes para simular la estructura de la forma urbana actual y potencial de una realidad comunal, en este caso Maipú. Para ello se ha decidido realizar un modelo cartográfico asociado a una visualización 3D, porque se cree que con ello se lograra de mejor forma el objetivo inicial. El resultado final esperado es obtener un instrumento operativo de apoyo a la planificación urbana, en un aspecto considerado clave y deficitario en la actualidad, como es la estructura morfológica de la ciudad.

El ejemplo tomado en cuenta ha sido la comuna de Maipú, situado en la periferia sur poniente de Santiago, la cual ha experimentado un crecimiento demográfico explosivo en los últimos veinte años impactando fuertemente en su urbanización y en la forma urbana. Algunos de los efectos han sido el descontrol de la forma urbana y caos de la estructura espacial urbana. Se cree que ambas materias serían posibles de manejar con una base conceptual orientada en "hacer urbanismo" más que en "hacer urbanización", por parte de los tomadores de decisión de la municipalidad en estudio.

\section{El Plan Regulador Comunal y su relación con el Diseño Urbano}

Cabe recordar que la planificación de los usos de suelo y las formas de ocupación del suelo es el resultado de la aplicación de normativas del Plan Regulador Comunal y Planes Seccionales. Vale decir, estos instrumentos legales son los que permiten estas formas de ocupación del territorio comunal. En efecto, el documento legal denominado Plan Regulador Comunal es un instrumento que norma sobre los límites urbanos, la red vial estructurante, los usos de suelo, las formas de ocupación y de subdivisión predial. Por tanto el emplazamiento de la arquitectura y los espacios públicos relevantes así como la definición de la trama o red de calles es posible de regular por el Plan, el cual puede permitir o prohibir las propuestas de los proyectos individuales que van conformando la ciudad.

La práctica de la aprobación de los proyectos arquitectónicos y urbanísticos según la Ordenanza del Plan Regulador Comunal es una función que le compete al Estado y la realizan funcionarios municipales, generalmente de profesión arquitecto, según la estricta aplicación de la ley en su forma y no en su espíritu. El funcionario podría aplicar criterios urbanísticos teniendo presente una visión de conjunto de la ciudad y no una visión de parcialidades inconexas al momento de otorgar el permiso municipal, pero es una facultad no siempre ejercida.

En este sentido, se pueden destacar algunos buenos ejemplos de intervenciones urbanísticas en la ciudad de Santiago. En el período de 1872-1875, el intendente chileno Don Benjamín Vicuña Mackena propone un proyecto de transformación de la ciudad de Santiago bastante exitoso en su época (Hermosilla, 1973) y en el periodo 1929 - 1931, el urbanista vienés Karl Brunner propone 
también un proyecto de transformación de la ciudad de Santiago, y más tarde realiza la confección del Plan Oficial de Urbanización de Santiago en 1934 que llego a aprobarse solamente seis años después, en 1939 por la Junta de Vecinos de la I. Municipalidad de Santiago y se constituyó entonces en el Plan Regulador de Santiago, (FAU, 1996).

Ambos destacados personajes pudieron realizar estas intervenciones no solamente por su talento y visión prospectiva sino también porque tenia apoyo político y competencias legales para actuar sobre la ciudad. En el caso de Vicuña Mackenna, en su calidad de Intendente tenia el apoyo del presidente Balmaceda y las leyes que lo facultaban para hacer modificaciones especialmente de calles en la ciudad. En el caso de Brunner, fue contratado por el Gobierno de Chile (Ministerio de Obras Publicas) con el respaldo político del presidente Ibañez del Campo y luego fue contratado por la I. Municipalidad de Santiago para formular el documento legal denominado Plan Oficial de Urbanización que controlaba no solo el ancho de calles de la trama sino también la altura de los edificios, su homogeneidad arquitectónica, la localización de espacios abiertos significativos y la arquitectura relevante para transformar la ciudad de Santiago.

A pesar de corresponder a distintos estados de desarrollo nacional y urbano, pues median 55 años entre las dos intervenciones, ambos proyectos contemplan la integración de la planificación de usos de suelo con el diseño del espacio público, la arquitectura y las obras civiles. Vale decir, se observa una dialéctica armónica entre el plano y el espacio público, o dicho de otro modo entre la planificación de la ciudad y el diseño del espacio urbano apoyado por la arquitectura.

A Mackenna, a fines del siglo XIX, le concernían aspectos como controlar la extensión de la ciudad, mejorar la conectividad entre los barrios y accesibilidad, actuar sobre la higiene y salubridad de los barrios más pobres, el hermoseamiento de los espacios públicos (calles), la creación de parques urbanos y plazas y el control de las inundaciones del río. Tuvo como asesor y jefe de proyecto al ingeniero Ansart quien realizó los tajamares del río Mapocho y el puente de Cal y Canto. De las numerosas obras y proyectos que realizo en apenas tres años de intendente, se destacan las más relevantes como la habilitación del Cerro Sta. Lucia como Parque, el camino de Cintura o circunvalación que delimitaba el arrea urbanizable y los tajamares del río Mapocho. Esto se concretó jurídicamente con la Ley de transformación y embellecimiento de Santiago en 1874.

A Brunner, a comienzos del siglo XX, le interesaba la estructura morfológica de la ciudad vinculada al Plan de Urbanismo, de hecho sus obras..." constituyen demostraciones fehacientes del ejercicio urbanístico que es posible desarrollar desde la arquitectura..." (Figueroa, 1996). Concebía la construcción de la ciudad como espacio público que tenia que planificar, en este sentido la dicotomía entre plan y proyecto que hoy se plantea fue resuelta por Brunner (Cortés, 1996), pues este consideraba la obra arquitectónica no solamente la construcción de edificios sino también los paseos públicos o espacios de la ciudad.

Entre sus actuaciones más importantes pueden mencionarse la plaza al norte de la Moneda, la uniformidad arquitectónica del barrio cívico; la Avenida Central, la no construcción de rascacielos en torno al edificio de La Moneda; la unión de los parques Forestal y Providencia; la eliminación del ferrocarril de circunvalación y estaciones de Sta. Elena, Ñuñoa, Providencia para construir otra pieza clave de la composición urbana y del bien común, el actual Parque Bustamante; el Plan Regulador de Santiago (aprobado en 1939); la visión de un ferrocarril subterráneo y una Avenida Norte Sur. 
Esta integración de la percepción bidimensional y tridimensional de la ciudad pareciera ser que hoy esta completamente perdida y no figura en los instrumentos de planificación urbana vigentes en Chile, los llamados Planes Reguladores. Como afirman algunos planificadores norteamericanos, (Gallion y Eisner, 1986) la planificación clásica de la ciudad ${ }^{(3)}$ ha sido reemplazada por una planificación económica de la ciudad $\stackrel{(4)}{ }$.

Esta situación es particularmente notoria en la morfología de la periferia metropolitana chilena. Una explicación de este fenómeno puede comprenderse a través del estudio y seguimiento de las Políticas de Desarrollo Urbano de los ochenta y noventa, (MINVU) junto con las Políticas Habitacionales (SERVIU), la planificación urbana y regional vía Planos Reguladores Comunales y Regionales (SERREMI/MINVU), los modelos de crecimiento físico de la metrópolis (AUCA,1979) (Joinet,1996) y la estructura de precios del mercado de la tierra, (Trivelli, 1997).

De modo que cabe preguntarse: $¿$ el instrumento legal denominado Plan Regulador es eficiente por sí mismo para lograr objetivos de ordenamiento de la ciudad? o bien ¿ es un instrumento que requiere ser modificado y/o complementado con otros mecanismos y facultades legales?

El autor Raposo (Raposo, 1995) comparte esta postura cuando afirma que el Estado de Chile ejerce importantes fuerzas modeladoras del ordenamiento urbano, siendo una de ellas la planificación urbana. Y que en el actual contexto de la modernización debieran revisarse las competencias de la planificación urbana. El autor afirma:

...frecuentemente suele ponerse en entredicho las capacidades de los planificadores urbanos o la eficacia de los instrumentos de planificación para mejorar o sostener el orden de la ciudad. Generalmente se olvida que la planificación urbana no es más que la expresión, a nivel de racionalidad instrumental, de las competencias jurídicas acordadas por la sociedad a la administración del Estado. Estas competencias normalmente indican el nivel de articulación de intereses alcanzado en torno a objetivos de equidad social...

Partiendo de esta premisa se podría sostener que efectivamente la relación entre planificación urbana y diseño urbano es una de las deficiencias o carencias que el Plan Regulador no contempla dentro de sus facultades, aunque existan artículos específicos destinados a precisar alturas de edificación, densidades de ocupación del terreno, distanciamientos a los medianeros, etc.

Del mismo modo, el plan regulador se pronuncia sobre los perfiles geométricos de las calles que constituyen la red vial estructurante. Más aún, el año 1997, el Ministerio de la Vivienda y Urbanismo realizó un estudio para entregar una metodología que estime la capacidad vial de la red, tema hasta entonces inexistente, pero nada se menciona acerca del significado espacial tridimensional de esa red. En otras palabras, carencia total del concepto de espacio público en dicho estudio. (MINVU, 1997). En efecto, las características de la red de espacios públicos y su vinculación con la arquitectura no es un tema incorporado explícitamente en las facultades del instrumento legal ni en las nuevas metodologías específicas para dimensionar la red. Se podría afirmar que el diseño urbano propiamente tal es solamente la resultante de la aplicación de proyectos individuales aprobados legalmente por el Plan, pero no habría una voluntad de diseño para concebir a la ciudad como un proyecto de urbanismo, (Pol, 1992).

La falta de una relación dialéctica entre las tipologías edificatorias y los espacios urbanos que configuran la morfología de la ciudad requiere previamente de un "proyecto de urbanismo" que 
bosqueje los lineamientos generales para la ciudad, no solamente en términos bidimensionales sino también tridimensionales, pues así se construyen las ciudades en la realidad.

Actualmente el documento legal Plan Regulador Metropolitano (MINVU, 1994) define los límites urbanos, el zoning, las redes viales estructurantes y los equipamientos colectivos de carácter metropolitano, pero carece de una propuesta de ciudad que incorpore los elementos claves del urbanismo en la morfología de la ciudad. A su vez, el Plan Regulador Comunal que maneja una escala menor y que esta supeditado al Plan Regulador Metropolitano, podría también bosquejar una organización espacial urbana a escala de la comuna y del barrio, teniendo presente que la ciudad se construye por etapas. Según Bonet: (Bonet, 1989)

... no hay que olvidar que la ciudad es un proceso continuo de crecimiento, transformación, modificación y cambio... y las estructuras urbanas son el producto de los modos de crecimiento y formación del tejido urbano que combinados con los sistemas compositivos forman la trama de la ciudad...

En términos de diseño urbano, se observa en la comuna de Maipú que en las nuevas urbanizaciones, los paños de terreno rural se van cubriendo por vastos sectores habitacionales que utilizan los antiguos limites prediales rurales para definir la trama de calles. Además se observa una textura similar, pero un grano muy pequeño en el tejido urbano, comparado con la urbanización anterior a los años ochenta. La relación espacio construído-espacio vacío que muestra el nolly plan, evidencia una gran monotonía y refleja un criterio de racionalización económica y constructiva que utiliza la ocupación máxima del lote para cada vivienda dentro del jibarizado concepto de "ciudad jardín" (Cherry, 1980).

Esto parece obedecer a la búsqueda de una máxima rentabilidad del suelo urbano y la edificación en el proceso de gestión inmobiliaria, con lo cual aumentan las densidades de ocupación del suelo y disminuye la superficie de $\mathrm{m} 2$ por habitante en cada vivienda. En contraste a lo anterior aparece también extensas superficies edificadas destinadas a locales comerciales y recreación intramuros (mall) sobre extensos terrenos libres destinados a estacionamientos.

El "mall" es conocido como las catedrales del consumismo pues ellos representan un estereotipo de las construcciones dedicadas a la venta de productos y servicios. En términos arquitectónicos son edificios ciegos, encerrados en sí mismo y entregando muros opacos a la ciudad. En términos urbanísticos se imponen en el tejido urbano y sin consideración alguna respecto de la configuración espacial del entorno. Esto puede interpretarse como la expresión arquitectónica y urbanística de la filosofía consumista donde además predomina la política del libre mercado en el modelo de urbanización seleccionado

Como afirma Fernández Alba, el arquitecto español contemporáneo, lo que caracteriza la crisis actual de la metrópolis de hoy en relación con su configuración ambiental es la dependencia y servidumbre que las últimas arquitecturas de la ciudad tienen con respecto al proceso de mercantilismo y de los diferentes sistemas de producción del espacio urbano, (Alba, 1990).

De este modo, la arquitectura se constituye en un gran aparato escénico que se torna indiferente a su entorno transformándose en una construcción sin memoria que se consolida como monumento en el desorden metropolitano. El nuevo orden económico global produce un cambio en la sociedad, que pasa de la cultura de la calidad por la cultura de la cantidad y el autor comenta: 
... frente a las corrientes neoliberales de fin de siglo, se hace imprescindible el desarrollo de una teoría crítica, que sostenga de una vez por todas, que el suelo y el espacio no deben legitimarse como mercancía, junto a una política de la ciudad que haga posible que el territorio de ésta sea cada vez menos un negocio privado y más un bien social...

Esta postura bien podría ajustarse al modelo de urbanización de crecimiento en la periferia sur poniente metropolitana de Santiago, pues allí se van localizando los segmentos poblacionales de menos recursos económicos y por ende con escasas posibilidades de entrar libremente en un juego mercantilista del espacio urbano.

\section{Los modelos como instrumentos de apoyo}

Los modelos son una representación simplificada de la realidad que tiene por objeto comprenderla mejor. Los modelos poseen distintas clasificaciones de acuerdo a tres criterios: i) ¿para qué función están hechos?; ii) ¿de qué están hechos?; y iii) ¿cómo tratan la dimensión temporal?.

En respuesta a la primera pregunta, los modelos pueden clasificarse en cuatro tipos de acuerdo a la función, a saber: los descriptivos; los predictivos, los exploratorios, y los de planeamiento. En respuesta a la segunda pregunta, hay distintos tipos de modelos según sean los medios utilizados para la modelación: físicos o conceptuales. Entre los primeros figuran las maquetas, las fotografías, los planos, y otros. Entre los segundos - y dependiendo si se emplean símbolos o lenguaje pueden ser matemáticos o verbales. Finalmente los modelos pueden ser estáticos o dinámicos según sean las variables empleadas y su condición frente al tiempo. Así por ejemplo, la localización de las actividades humanas pueden variar muy rápido de un día para otro o incluso en horas, a diferencia del stock físico (suelo, edificios, calles) que cambian muy lentamente, (Echeñique, 1975).

Así, el modelo cartográfico se sitúa en un modelo de tipo descriptivo y exploratorio, pues pretende describir una realidad y explicar un fenómeno a través del análisis, en este caso el sistema urbano. Esta técnica simula la realidad mediante un esquema de causa-efecto configurado en base de un diagrama de flujos. Como su nombre lo indica, el modelo emplea una base cartográfica y opera como un sistema de información geográfica.

El modelo cartográfico es de tipo lineal, organizado en una red jerárquica, que a partir de variables de entrada, de tipo descriptivas, pueden producir variables derivadas - producto del análisis - con nuevas salidas cartográficas; las cuales al superponerse con otras salidas de la red generan nueva información. De este modo, el modelo cartográfico puede contribuir a analizar un fenómeno a través de la desagregación de sus variables constituyentes. El modelo cartográfico está enraizado en el campo de la geografía y es ampliamente utilizado en el análisis espacial, por ejemplo la predicción de efectos de fenómenos naturales. (Bosque, 1992); (Gutierrez, 1994).

\section{Planteamiento del problema}

El problema enunciado en la introducción y en el punto 1 se refiere a la carencia de un concepto la forma urbana - en los contenidos para realizar un Plan Regulador Comunal $\stackrel{(5)}{ }$.

En efecto, este instrumento de planificación urbana está compuesto de cuatro documentos que conforman un cuerpo legal para administrar el territorio comunal (MINVU, 1992), a saber: 


\section{Memoria Explicativa}

\section{Ordenanza Local}

\section{Planos}

4. Estudio de Factibilidad de Agua Potable y Alcantarillado

1. La Memoria Explicativa comprende el diagnóstico y los fundamentos de la propuesta de Plan Regulador. Recientemente se incorporaron otros dos estudios técnicos: el Estudio de Riesgo y el Estudio de Capacidad Vial. Además contiene todos los antecedentes gráficos, planimétricos y descriptivos, sobre aspectos demográficos, sociales, y económicos. Todo lo anterior tiene por objeto servir de base para las proposiciones y las alternativas de estructuración y gestión.

2. La Ordenanza Local es la normativa que fija los límites urbanos de sus centros poblados, el trazado de la vialidad estructurante; los usos de suelo permitidos, restringidos y prohibidos; el coeficiente de ocupación del suelo; las rasantes y distanciamientos; las alturas de edificación máxima y mínima; los tamaños prediales; los tipos de agrupamiento; y las normas sobre el equipamiento para todas las áreas urbanas y sistema urbano comunal sometido a planificación.

Los Planos son los documentos planimétricos (bidimensional), que expresan gráficamente, entre otros, el límite urbano, las áreas de extensión urbana con sus prioridades, las áreas de riesgo y de restricción, la zonificación, los usos de suelo, las densidades, la red vial estructurante, las áreas verdes y el equipamiento.

El Estudio de Factibilidad de Agua Potable y Alcantarillado, comprende la descripción, el análisis, el cálculo y proyecciones del sistema a fin de dotar o ampliar de agua potable y alcantarillado, de aguas servidas y lluvias, en función del crecimiento urbano proyectado.

Como puede verse, el tema de la definición de la forma urbana inserto en un proyecto de ciudad, está ausente en los contenidos actuales del Plan Regulador Comunal. Una de las consecuencias de este hecho es la desarticulación del espacio urbano, junto a la pérdida de los recursos naturales o arquitectónicos relevantes para la identidad de un lugar, lo cual sirve de base para la conciencia colectiva, el significado cultural, el sentido de pertenencia y apropiación del territorio por parte de la comunidad. Algunos autores que se refieren in extenso al tema. (Newman, 1976), (Rappoport, 1980), (Kostof, 1991), (Katz, 1994) (Trieb, 1988). En suma, una situación de este tipo repercute directamente en la calidad de vida para el habitante.

La importancia de controlar la forma urbana por el instrumento de planificación radica básicamente en dos aspectos: uno económico y otro semántico. El primero tiene relación con las rentas municipales que podrían captarse derivadas de la competencia por una localización de actividades comerciales y residenciales en ciudades vivibles y atractivas, cuya característica visible es precisamente la forma urbana. 
Por ejemplo, muchas ciudades europeas occidentales de países con economías muy desarrolladas, contemplan políticas de inversión en patrimonio arquitectónico y urbanístico, pues eso representa parte significativa de su base económica, toda vez que una forma urbana estructurada y regulada armónicamente mediante una normativa municipal, da un encanto físico a la ciudad.

Esta situación atrae turistas y negocios de transacciones bursátiles, como también de eventos internacionales (convenciones, congresos, festivales, etc.), a la ciudad que tiene ventaja comparativa frente a otra localización, (CEC, 1990). Este principio también es posible aplicarlo a una menor escala, en la comuna, pues las mayores rentas municipales podrían significar una mayor inversión en gasto público para infraestructura colectiva y un sustancial mejoramiento del medio ambiente urbano, lo cual incide en la calidad de vida de sus moradores.

Desde el punto de vista semántico, es importante señalar que el comportamiento del ser humano en su interacción con el medio ambiente construido obedece esencialmente a relaciones topológicas, las cuales se estructuran en base a la forma urbana. (Gutierrez, 1994), (Lynch, 1960), (Hall, 1966). Esto significa, por ejemplo, que el individuo utiliza referencias espaciales de tipo cualitativo del siguiente orden: cerca de, arriba de, detrás de, a la izquierda de, entre, al oeste de, etc., para orientarse y dar indicaciones sobre como desplazarse en una ciudad cualquiera.

Esto lleva a plantear la necesidad de incorporar el tema de la forma urbana y para ello se propone el desarrollo de un modelo cartográfico que permita integrar conceptos que tengan una fuerte incidencia en la configuración espacial urbana. Así, manejarlos gráficamente, de modo de instrumentalizar un método de_trabajo que sea fácilmente operable en distintos contextos comunales en Chile. Uno de los beneficios de este método, es que el uso del lenguaje gráfico, contribuye de un modo significativo a una mejor comprensión de la propuesta, sea por parte del arquitecto, urbanista, gestor inmobiliario. comunidad, planificador, etc. (Hall, 1993)

\section{Desarrollo y propuesta del modelo.}

El modelo cartográfico diseñado para lograr como resultado una "Definición de la Estructura Morfológica para Plan Regulador Comunal" aparece en la Figura №1. Como puede verse, el modelo esta constituido por tres componentes principales: el modelo volumétrico, la planimetría de la estructura morfológica, y la localización de áreas potenciales de mayor demanda. Estos dos últimos pueden realizarse con un Sistema de Información Geográfica SIG, en cambio el primero requiere de otra técnica, la visualización 3D. En este articulo se desarrollaran las opciones posibles dentro del sistema de información geográfica.

El caso de estudio elegido es la comuna de Maipú, ubicado en la periferia de la metrópolis de Santiago, de creciente expansión física y demográfica en la última década. Dinamismo que facilita una modelación cartográfica por la rapidez de los cambios ocurridos. (Figura № 0) 
La forma urbana del medio ambiente construido:

$\mathrm{http}: / /$ revistaurbanismo.uchile.cl

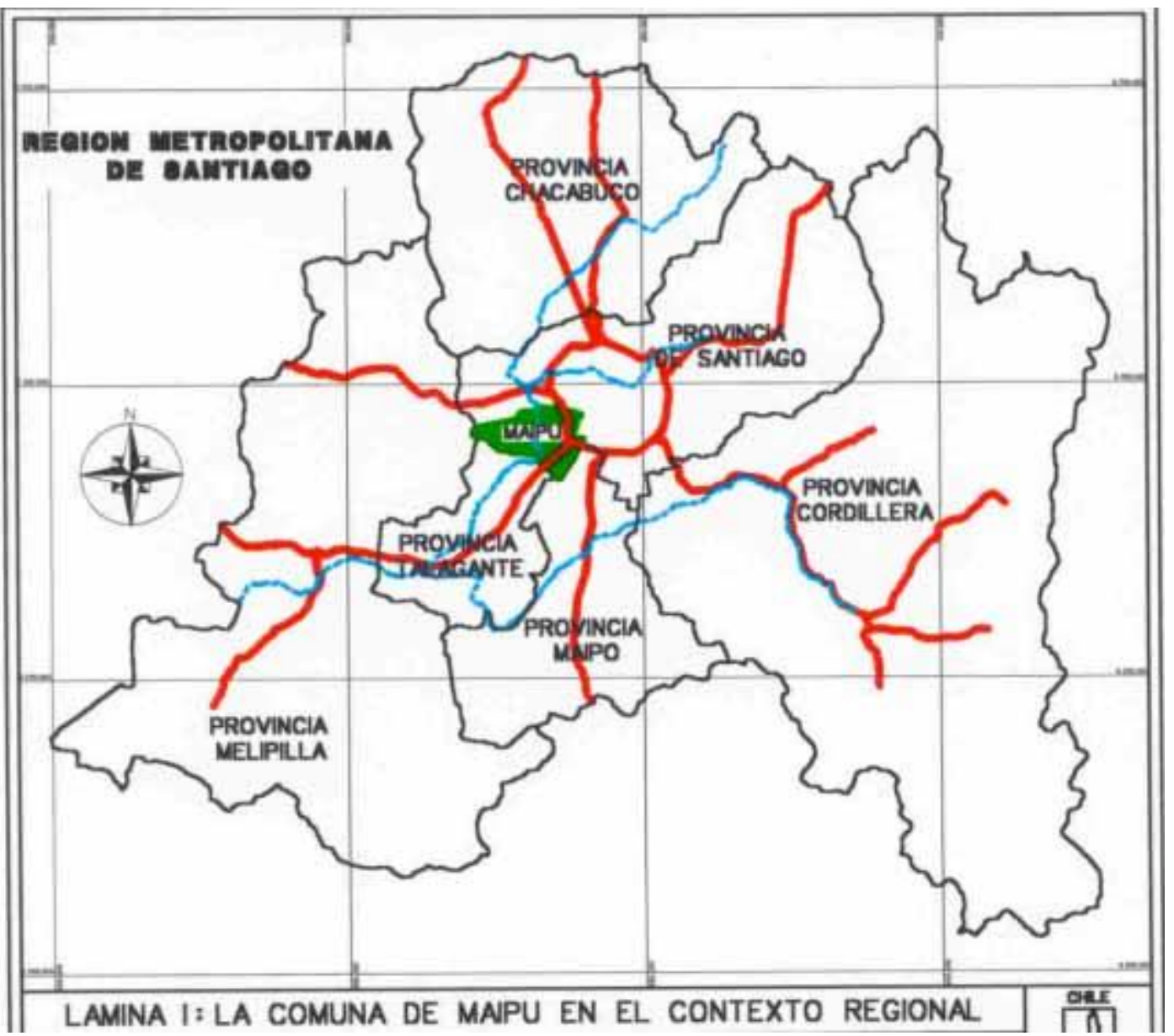




\section{REVISTA DE URBANISMO

La forma urbana del medio ambiente construido:

http://revistaurbanismo.uchile.cl

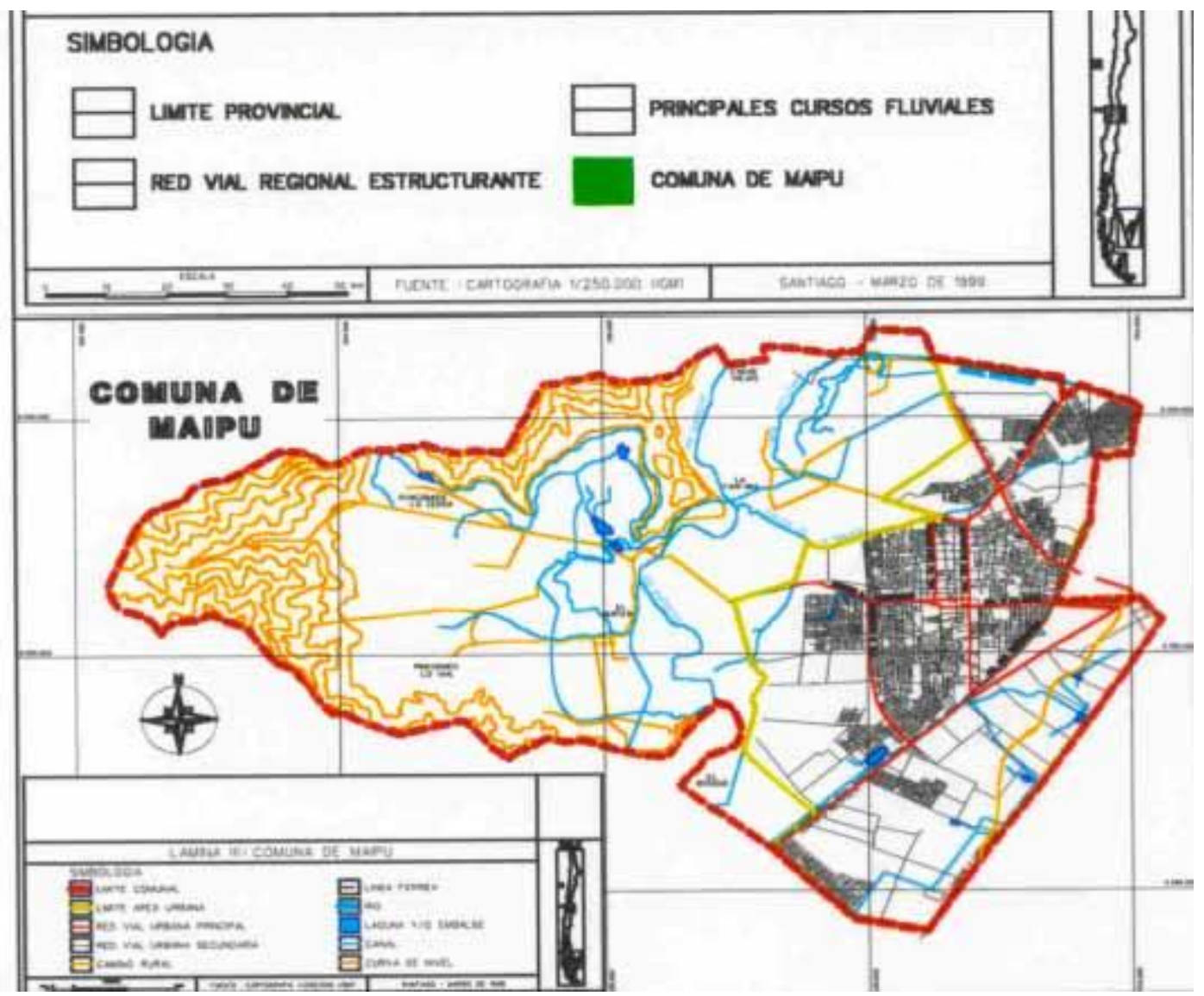

(Supra) Figuras 0

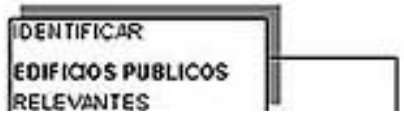




\section{(1)}

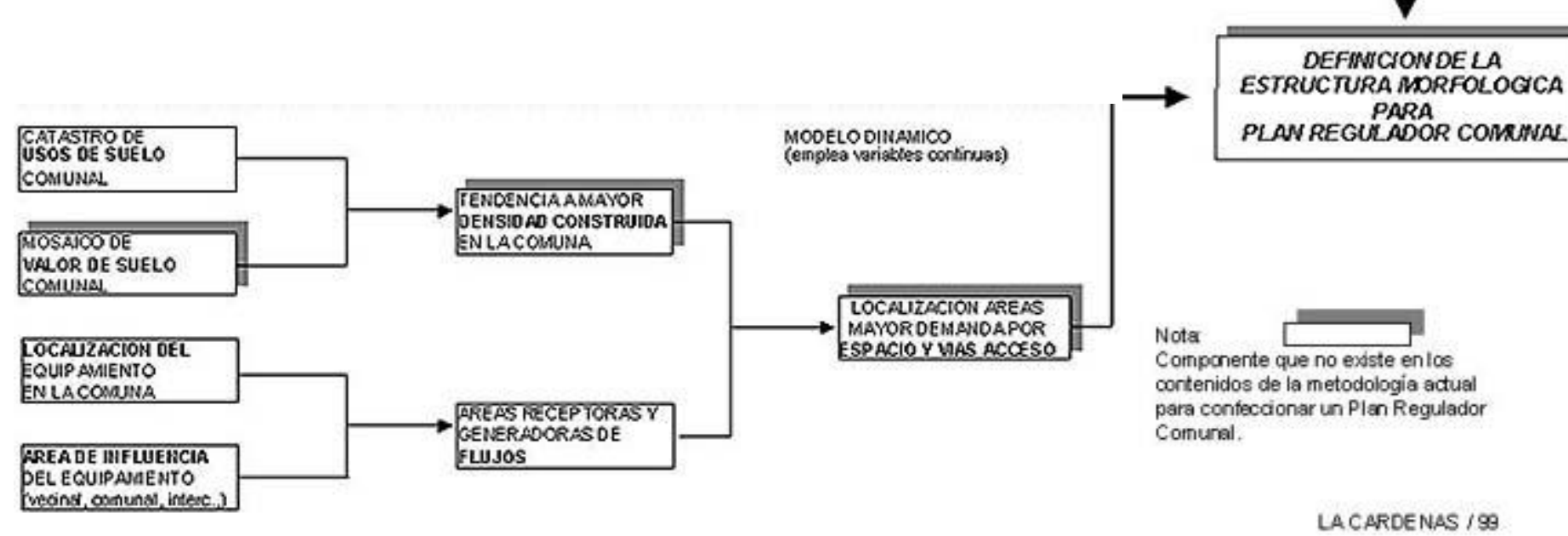

\section{Figura 1}

Descripción de la estructura morfológica para el plan regulador

En la Figura $\mathrm{N}^{\circ} 1$ se muestran las variables que debieran considerarse para llegar a definir la estructura morfológica de un asentamiento y así facilitar la formulación de una normativa en el Plan Regulador Comunal. Se han sombreado los cuadros que contienen variables que no están contempladas explícitamente en los contenidos actuales de la metodología para confeccionar un Plan Regulador Comunal, (ver 1, op. cit.) De un total de 9 variables, se han escogido 5 para la realización de un modelo estático y 4 para la realización de un modelo dinámico. Esta clasificación obedece a la naturaleza de las variables respecto a su velocidad de respuesta frente al cambio. Esto significa, aquellos componentes relativas a la infraestructura física o natural, cambian muy lentamente respecto de aquellos componentes asociados a las actividades urbanas, que pueden cambiar mucho mas rápidamente.

En el modelo estático se presenta una red compuesta por dos variables fundamentales de la forma urbana: las centralidades y los conectores, los cuales arrojaran como resultado final la "planimetría de la estructura morfológica" (Figuras №11, №12, y №15). Los elementos primarios para definir las 


\section{RUVSTADE URBAANISMO

centralidades son tres: los edificios públicos, la topografía, y los espacios públicos. (Figuras №2, №3 y №4). Los elementos primarios para definir los conectores son dos: los espacios públicos y la vialidad intra e intercomunal. (Figuras №5 y №6).

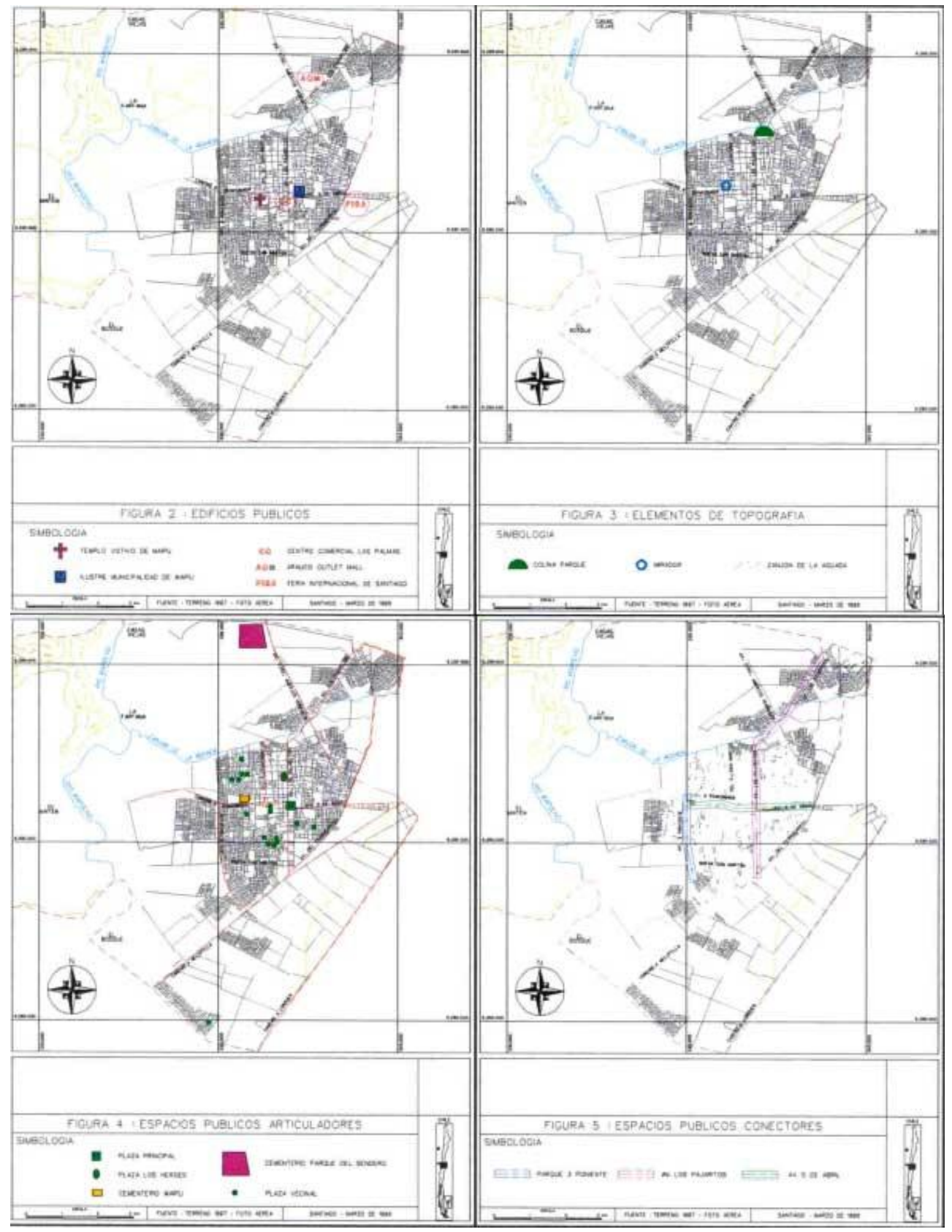

(Supra) Figuras 2 a 5 


\section{REVSTADE URRBANANISMO

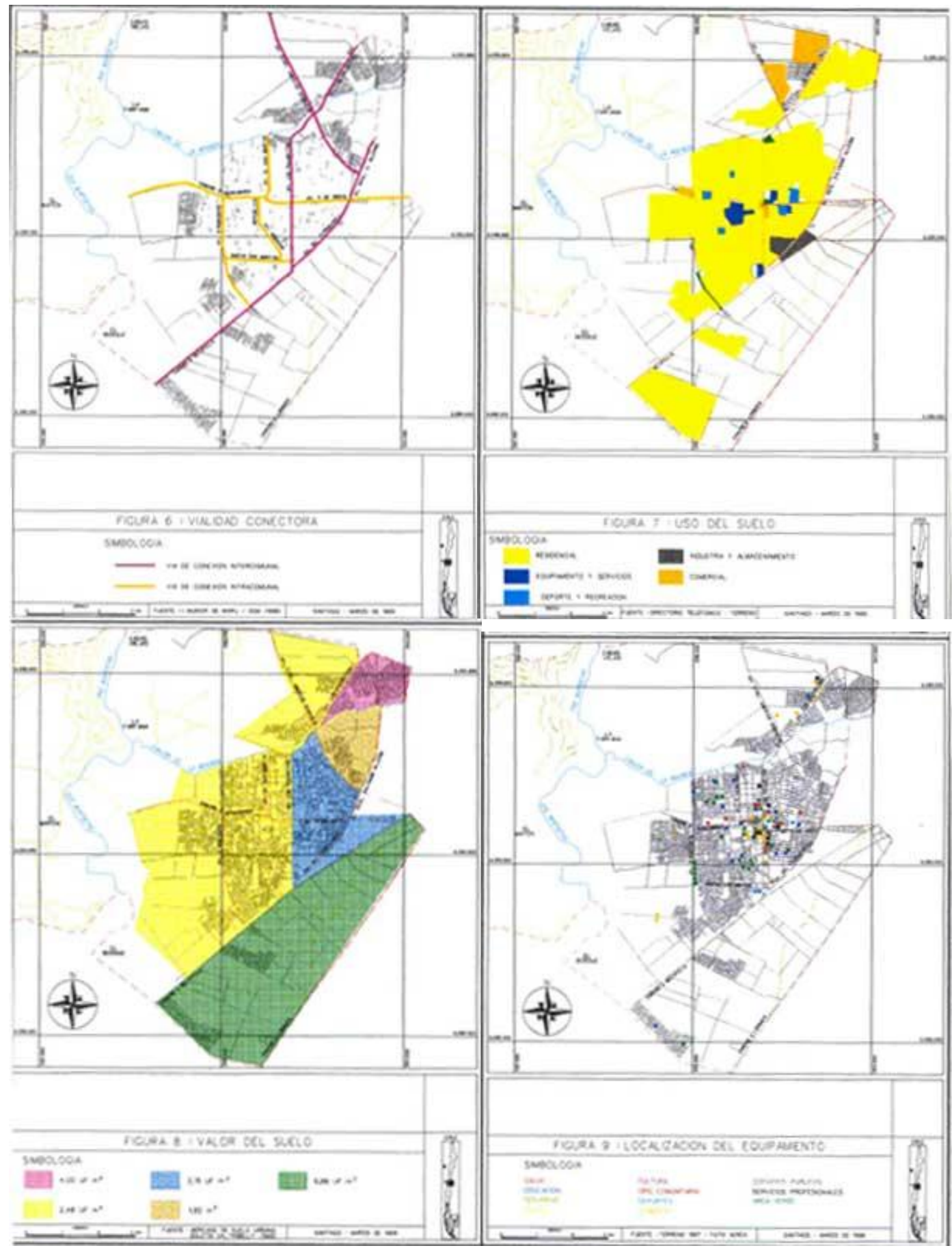

(Supra) Figuras 6 a 9 


\section{RUVSTADE URBANISMO

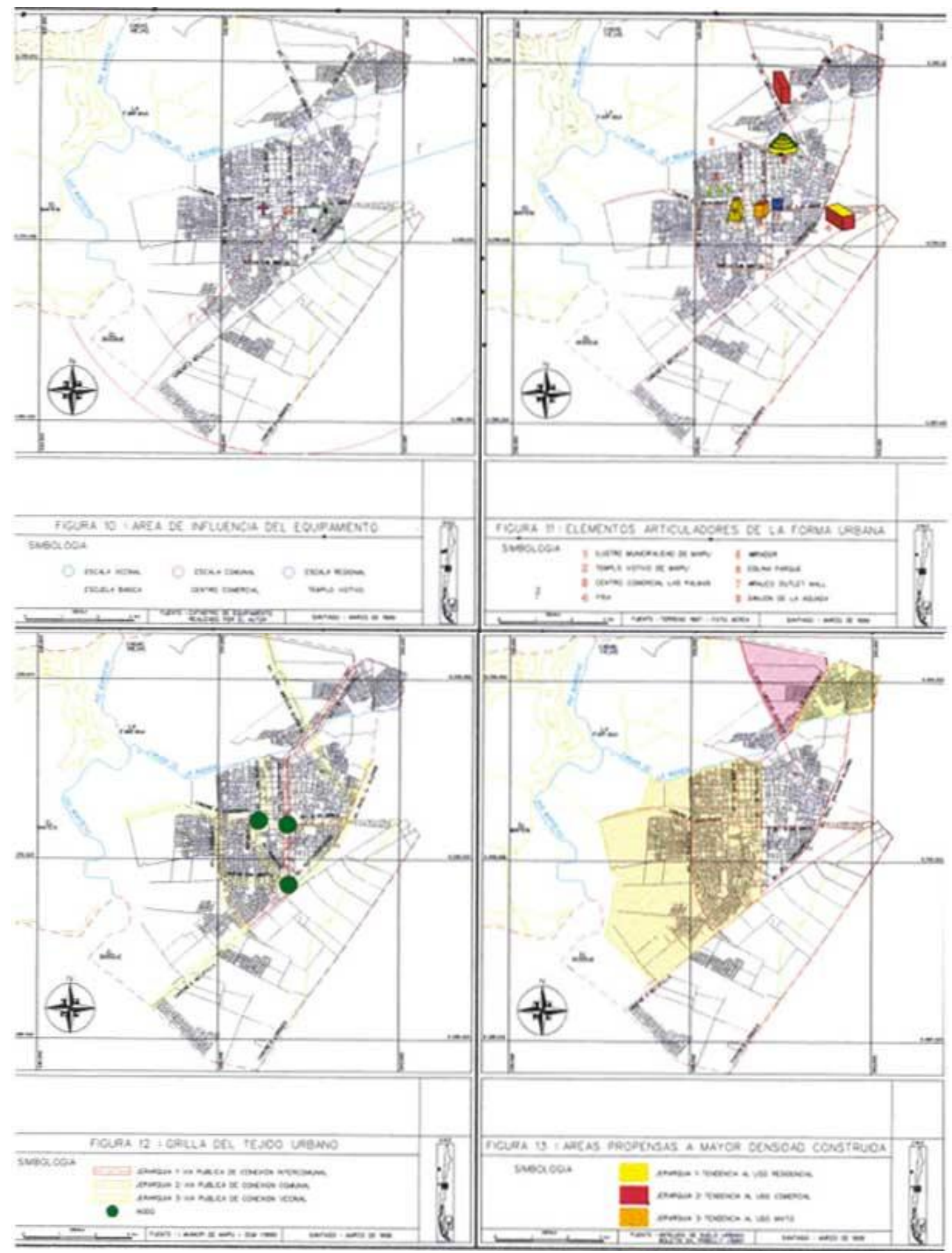

(Supra) Figuras 10 a 13 


\section{REVISTA DE URBANANISMO

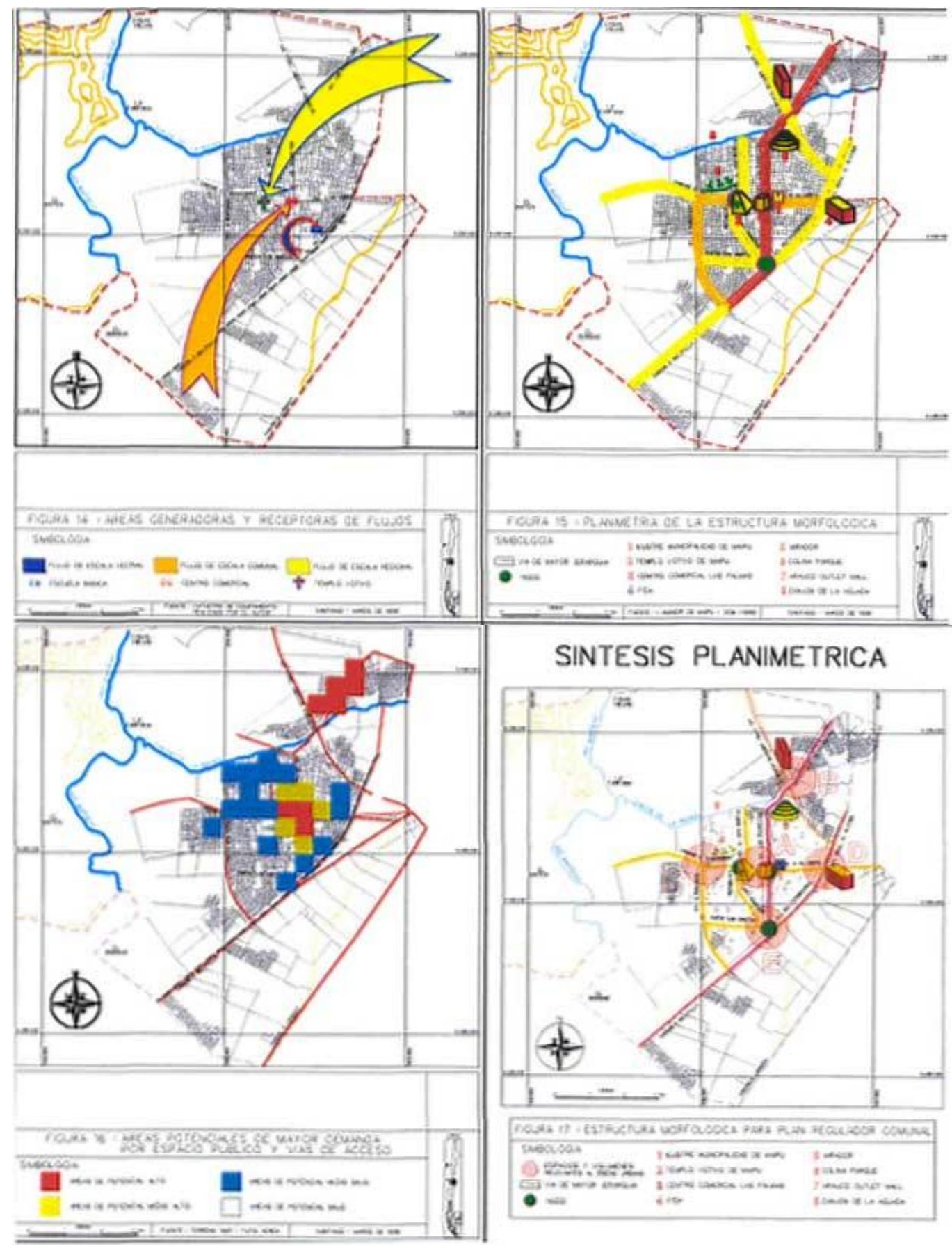

(Supra) Figuras 14 a 16 
En el modelo dinámico, se presenta una red compuesta por dos variables indicadoras de tendencias que influyen en la forma urbana: la densidad construida y las áreas generadoras y receptoras de flujos (Figuras $\mathrm{N}^{0} 13$ y $\mathrm{N}^{0} 14$ ). Los elementos primarios para definir la tendencia a elevar la densidad construida son los usos de suelo, y el valor de suelo, (Figuras $\mathrm{N}^{07}$ y N08). Los elementos elegidos para definir las áreas propensas a generar y recibir flujos son la localización del equipamiento y su área potencial de influencia, (Figura $\mathrm{N}^{\circ} \mathrm{9}$ y $\mathrm{N}^{\circ} 10$ ). El resultado final de esta red es localizar las áreas potenciales de mayor demanda por espacio público y vías de acceso (Figura No16).

En suma, lo que se pretende ilustrar es una contrastación de la oferta y demanda existente en un territorio comunal por los componentes de la forma urbana, a saber: el espacio público, las calles, los edificios, la topografía. En donde la oferta estaría representada por el soporte físico, sea natural o artificial; y la demanda estaría representada por las actividades realizadas por la población, en la comuna, y su disponibilidad a pagar por una determinada localización. (Alonso, 1964). La demanda presiona sobre el soporte físico u oferta en el proceso de desarrollo urbano, lo cual incide directamente sobre la configuración espacial de la ciudad y así va determinado finalmente la forma urbana.

La comprensión de este fenómeno puede permitir efectuar un diagnóstico y proposición de normativa para controlar efectivamente la forma urbana y que no aparezca como ocurre en la actualidad, que es un producto residual, espontáneo, resultante de presiones económicas por lograr una mayor rentabilidad del suelo y no un resultado planificado, armónico, y equitativo.

\section{3.- Comentarios y conclusiones}

3.1. - La normativa de Plan Regulador Comunal podría considerar estudios técnicos como el "modelo SIG", durante su ejecución, a fin de incorporar la forma urbana como un factor relevante en la configuración espacial de la ciudad.

3.2.- Esta técnica permitiría iniciar un camino que facilite la incorporación del diseño urbano en la planificación urbana y así mejorar la calidad espacial en las ciudades chilenas.

3.3.- La topología es un concepto de vital importancia para el análisis y la planificación espacial urbana, que de incorporarlo en la confección de Plan Regulador Comunal, actuaría como elemento orientador de la forma urbana.

3.4.- La economía urbana es un marco conceptual que ayuda a comprender el proceso de localización y permanencia de actividades en un conglomerado urbano, por tanto debiera entenderse como un factor explicativo de la forma física resultante en la ciudad. 
3.5.- El "modelo SIG" recientemente presentado representa una base conceptual para comprender la gestación de la forma urbana y así poder formular posteriormente la normativa de edificación y subdivisión del suelo.

3.6.- La técnica de la zonificación empleada por el Plan Regulador Comunal recoge tendencias de usos y las agrupa según zonas, lo cual trae como consecuencia la creación de un mosaico de piezas separadas que no llegan a integrarse. En cambio, el modelo postula la creación de una herramienta que integre los elementos dispersos en una ciudad. En este caso, la comuna de Maipú.

\section{Referencias}

ALBA F., A. La Metrópoli Vacía. Aurora y Crepúsculo de la arquitectura en la ciudad moderna. Ed. Anthropos, Barcelona, 1990.

ALONSO, W. Location and land use: Towards a Theory of Urban Rent. Cambridge (Mass.) Harvard University Press, 1964.

BACON, E ., Design of Cities. De. Thames and Hudson, London, 1975.

BONET, A. Las claves del Urbanismo. Ed. Ariel. Barcelona, 1989.

BOSQUE, J., Sistemas de Información Geográfica. Ed. Rialp. Madrid, 1992.

BUSQUET, J "Barcelona: entre la "forma" y la "reforma" en La ciudad como proyecto. Ed.MOPTMA. Madrid, 1992, pp. 16-23.

CASAR, J. et al Claves para conocer la Ciudad. Ed. Akal. Madrid, 1989.

CÁRDENAS, L.A. "Urbanismo versus urbanización: dos modalidades de hacer ciudad", en revista electrónica Urbanismo $N^{\circ} 1$, Facultad de Arquitectura y Urbanismo, Universidad de Chile, 1999.

CÁRDENAS, L.A. and C. Mawromatis, "Urban form at the fringe of metropolitan Santiago. A result of a normative or profitability plan?". En $21^{\text {st }}$ International Making Cities Livable Conferences. March 1998. California.

CEC Green paper on the urban environment. Comission of the European Comunities. Luxembourg, 1990.

CHERRY, G. Shaping an Urban World, Ed. Mansell. London, 1980.

ECHEÑIQUE, M. Modelos matemáticos de la estructura espacial urbana: aplicaciones en América Latina. Ed. SIAP, Buenos Aires, 1975.

FAU Revista de Arquitectura No8 (especial Karl H. Brunner). Facultad de Arquitectura y Urbanismo. Universidad de Chile. Santiago, 1996.

FIGUEROA, J "La ciudad demostrativa: 1929". Revista de Arquitectura No 8. FAU UChile., Santiago, 1996. 
GALLION, A. et S. Eisner. The Urban Pattern. City Planning and Design. Ed. Van Nostrand Reinhold. New York, 1986.

GUTIERREZ, J. Y M. Gould, SIG: Sistemas de Información Geográfica. Ed. Síntesis. España, 1994.

HALL, A.C. "The use of computer visualisation in planning control. En Town Planning Review. Vol.64(2)April. pp. 193-211,1993.

HALL, E. The hidden dimension. New York. Doubleday, 1966.

HERMOSILLA, P. Vicuña Mackenna y la Transformación de Santiago. Seminario DEPUR/FAU. Universidad de Chile. Santiago, 1973.

HOUGHTON-EVANS, W. "Schemata in British new town planning" en Shaping an Urban World. Pp. 101-128. Ed. Mansell. London, 1980.

JOINET, H. "Santiago du Chili: une capitale horizontale" en Urbanisme N0291, Nov/Dec.pp.17-22, 1996.

KATZ, P. The New Urbanism. Toward an Architecture of Community. McGraw-Hill New York,1994.

KOSTOF, S. The City Shaped. Urban patterns and meaning through history. Thames and Hudson. London, 1991.

LYNCH, K. The image of the city. Cambridge (Mass.), MIT Press,1960.

MUSTIELES, F. "El eje histórico de París mas allá de La Defense: un reto de composición urbana para fin de siglo." Ciudad y Territorio. N085 MAP, Madrid, 1990.

CHILE - MINVU Ordenanza General de Urbanismo y Construcciones. Ed. Publiley. Santiago, 1992.

CHILE - MINVU Plan Regulador Metropolitano de Santiago. E\&C, 1994.

CHILE - MINVU Capacidad Vial de los planes reguladores. Metodología de Cálculo, Santiago, 1997.

NEWMAN, O Defensible Space people and design in the violent city. Architectural Press, London, 1976.

POL, A La ciudad como proyecto. Ed.MOPTMA. Madrid, 1992.

RAPOSO, A. Planificación Urbana y Administración Local en el Marco de la Modernización del Estado. CEDVI FABA. U Central. Santiago. 1995. 
RAPPOPORT, A. Aspectos Humanos de la Forma Urbana. Ed. GG. Madrid.1980.

TRIEB, M., Schmidt, Paetow, Buch, Erhaltung und Gestaltung des ortsbildes. Denkmalpflege, Ortsbildplannung und Baurecht, $2^{a}$ edición, Ed. W. Kohlhammer, Stuttgart, Berlin, Koln, Mainz, 1988. Cap. 1, pp 13-27.

Nota: Este artículo es resultado de un proyecto de investigación FONDECYT N¹961172/96, de 2 años de duración en el cual la autora fue la investigadora responsable, siendo los co-investigadores: Figueroa Salas, Jonás; Mawromatis Pazderka, Constantino, y Fernández, M.E. 